\title{
A SYSTEM DYNAMICS MODELING OF MUNICIPAL SOLID WASTE MANAGEMENT SYSTEMS IN DELHI
}

\author{
Kafeel Ahmad \\ Department of Civil Engineering, Jamia Millia Islamia (A Central University), Jamia Nagar, New Delhi - 110025, India, \\ kafeeljmi@yahoo.com
}

\begin{abstract}
Municipal solid waste management system (MSWMS) includes MSW generation, storage, collection, transfer and transport, processing and disposal. The planning of an optimal MSWM strategy requires a reliable tool for predicting the amount of municipal solid waste (MSW) that is likely to be produced. The MSWMS is a complex, dynamic and multi-faceted system depending not only on available technology but also upon economic and social factors. Computer models are of great value to understand the dynamics of such complex systems. Therefore, in this study a system dynamics (SD) computer model has been used to predict MSW generated, collected, disposed, recycled and treated capacities, and to estimate the electricity generated from MSW and to predict the fund required for MSWM in Delhi during 2006 and 2024. It is expected that the per capita generation rate will be $0.61 \mathrm{~kg} / \mathrm{day}$ and the compost production rate will be 342 thousands in 2024. The electrical energy generation potential from various MSW treatment methods will be $302275.3 \mathrm{Mwh}$ and the projection revenue produced from different facilities will be 2068.6 (million Rs.) and this revenue can cover all the costs required for these facilities in 2024.
\end{abstract}

Keywords: solid waste management, system dynamics, modeling, Delhi.

\section{INTRODUCTION}

The state of Delhi with a population of approximately 15 millions is one of the biggest metropolises of the world. With increasing urbanization and changing lifestyle, the amount of MSW has been increased rapidly, and the composition has been changing. The people of Delhi generate millions of tones of MSW yearly and the MSW quantity is increasing with the population growth. The flow network of MSW stream in Delhi is divided into three main sets: generation sources, intermediate facilities (composting and recycling) and ultimate disposal (landfills). The collection and disposal of MSW have been entrusted to three municipalities i.e. Municipal Corporation of Delhi (MCD), New Delhi Municipal Corporation (NDMC) and Delhi Cantonment Board (DCB). The Conservancy and Sanitation Engineering (CSE) Department of MCD is responsible for MSWM in most of the State running a comprehensive operation of street cleansing, MSW collection, transportation and disposal at landfill sites, repair and maintenance of the MSW storage facilities, dustbins, transportation vehicles involving a large number of staff and mobile equipment and plant. The municipal corporation often depends on the vehicle trips record to estimate the waste quantity. This does not give the actual picture of waste generation. Studies carried out by MCD to estimate the quantity and characteristics of MSW during 2005 and it indicated that Delhi generates about 8567 tons of waste every day. About 6554 tons (i.e., $76.5 \%$ of total waste generated) is collected from 2400 secondary collection points, however, 2000 tons (i.e., $23.5 \%$ ) does not reach the municipal stream. This unaccounted waste is either recycled by rag
$* * *$

pickers at various locations or left unattended at various stages of waste generation, collection and transportation wherever services are not provided properly. The per capita generation of MSW in Delhi is approximately $0.5 \mathrm{Kg} /$ capita/day (MCD, 2006; NDMC, 2006; MCD, 2005; NDMC, 2005; Sharholy et al., 2005; MCD, 2004).

Delhi has been disposing of its MSW in three sanitary landfills namely, Okhla, Gazipur and Bhalswa; these landfills are mere dumps without proper liners and leachate collection systems. For treatment and processing of MSW, there are three compost plants two in Okhla operated by MCD and NDMC and one in Bhalswa operated by a private developer (M/s Excel Industries Limited). Recycling of MSW is a widely prevalent activity in Delhi and an extensive network of informal and formal stakeholders are involved in this process. The number of rag pickers in Delhi is ranging from 80,000 to 100,000 and each one collects around $15 \mathrm{~kg}$ of waste everyday, it reduces the load for treatment and disposal by 1200-1500 tons per day. Recycling units in Delhi work both in formal and informal sectors and geography spread across Delhi and it is generally done in a dirty and unhygienic manner (Sharholy et al., 2007; CPCB, 2004).

System Dynamics (SD) is a methodology for analyzing complex systems and problems over time with the aid of computer simulation software. It deals with internal feedback loops and time delays that affect the behaviour of the entire system. What makes using SD different from other approaches for studying complex systems is the use of feedback loops, 
stocks and flows. These elements help describe how even seemingly simple systems display baffling nonlinearity. Talyan et al. (2007) and Chaerul and Tanaka (2007) presented a detailed description about SD and its applications. Computer software is used to simulate a SD model of the situation being studied. The mathematical mapping of a SD stock-flow diagram occurs via a system of differential equations, which is solved numerically via simulation. Nowadays, high-level graphical simulation programs (such as i-think, Stella, Vensim, and Powersim) support the analysis and study of these systems. The real power of SD is utilised through simulation. Although it is possible to perform the modeling in a spreadsheet, there is a variety of software packages that have been optimised for this. The steps involved in a simulation are:

- Define the problem boundary

- Identify the most important stocks and flows that change these stock levels

- Identify sources of information that impact the flows

- Identify the main feedback loops

- Draw a causal loop diagram that links the stocks, flows and sources of information

- Write the equations that determine the flows

- Estimate the parameters and initial conditions. These can be estimated using statistical methods, expert opinion, market research data or other relevant sources of information.

- Simulate the model and analyse results

SD modeling has found application in a wide range of areas and it has been used to address practically every sort of feedback system, including population, business systems, ecological systems, social-economic systems, agricultural systems, political decision making systems, and environmental systems (Dyson and Chang, 2005). The policy makers and researchers have extensively used SD approach for every sort of complex and dynamic system such as political decisionmaking systems (Nail et al., 1992), environmental impact assessment (Vizayakumar and Mohapatra, 1991; Vizayakumar and Mohapatra, 1993), global warming and greenhouse gas emissions (Sterman et al., 2002; Anand et al., 2005), water resource planning (Ford, 1996), environmental planning and management (Vezjak et al., 1998; Wood and Shelley, 1999; Abbott and Stanley, 1999; Guo et al., 2001), ecological modeling (Wu et al., 1993; Saysel and Barlas, 2001), value of water conservation (Stave, 2003), the consequences of dioxin to the supply chain of the chicken industry (Minegishi and Thiel, 2000), modeling of a shallow freshwater lake for ecological and economic sustainability (Guneralp and Barlas, 2003), the impact of environmental issues on long-term behavior of a single product supply chain with product recovery (Georgiadis and Vlachos, 2004), sustainability of ecological agricultural development at a county level (Shi and Gill, 2005), environmental sustainability in an agricultural development project (Saysel et al., 2002), regional sustainable development issues (Bach and Saeed, 1992) and SWM
(Mashayekhi, 1993; Sudhir et al., 1997; Karavezyris et al., 2002; Themelis et al., 2002; Dyson and Chang, 2005; Sufian and Bala, 2007; Talyan et al., 2007 Chaerul and Tanaka, 2007).

Mashayekhi (1993) explored a dynamic analysis for analyzing the transition of landfill method of disposal to other forms of disposal for the city of New York. Sudhir et al. (1997) employed a SD model to capture the dynamic nature of interactions among the various elements of urban SWMS in a typical metropolitan city in India. The model has provided a platform for debate on the potential and systemic consequences of various structural and policy alternatives for sustainable SWM. Karavezyris et al. (2002) developed a methodology to incorporate qualitative variables such as voluntary recycling participation and regulation impact quantitatively to forecast SW generation. Themelis et al. (2002) reported that the heating values of the different types of wastes decrease as the moisture content increases. Dyson and Chang (2005) emphasized the capability of SD for the prediction of SW generation in an urban setting with a high economic growth potential. The authors developed SD models based on the simulation of five different combinations of factors that influence SW generation. The factors include: total income per service center; people per household; historical amount generated; income per household and population. Sufian and Bala (2007) developed a SD computer model to predict SW generation, collection capacity and electricity generation from SW and to assess the needs for SWM of the urban city of Dhaka, Bangladesh. Talyan et al. (2007) developed a SD approach to quantify the methane emission from MSW disposal in Delhi. Chaerul and Tanaka (2007) developed a SD approach to determine the interactive relation among factors in hospital waste management system in a developing country.

\section{METHODOLOGY}

Initial step of SD modeling approach is the identification of problem followed by development of dynamic hypothesis explaining the causes of the problem. The dynamic model is converted to the causal loop diagrams or stock flow diagrams, which are based on the interlinkage of different components associated within the system. This model formulation is normally designed to test a computer simulation model with regard to the alternative policies within the system. In SD modeling, simulations are time dependent. To develop SD models, the relevant study material can be found in the literature (Forrester, 1961; Forrester, 1968; Randers, 1980; Richardson and Pugh, 1989; Mohapatra et al., 1994). As far as SWM is concerned, the prediction of waste generation plays an important role in the management system. Traditional forecasting methods frequently count on the demographic and socioeconomic factors on a per-capita basis. In order to forecast the MSW generation of a complex waste management system, a SD model has been proposed. In this study 
Powersim Studio Academic 2005 software was used to support the analysis and study of MSWM system in Delhi.

\section{DEVELOPMENT SYSTEM DYNAMICS MODEL FOR MSWMS IN DELHI}

\subsection{Explanatory Model - Causal Loop Diagram}

The causal loop diagram has presented in Fig. 1 depicts the relationships between the essential elements of MSWMS in Delhi and the influencing factors. An important issue is that the amount of MSW generation increases with the increase in population and growth economic (GSDP and per capita income). If the MSW generated is disposed of in an inappropriate way it will negatively affect the environment and cause environmental problems then the funds required for managing this waste will be increased causing deficit in the municipal budget. Applying an integrated MSWMS (IMSWMS) can minimize the environmental effects. The environmental problems have a strong influence on the three main factors: legal, economic and social patterns. Firstly, the legislative rules set up goals and standards to regulate the impact of the different treatment technologies. Thus, goals and standards contribute to the establishment of IMSWMS through MSWM plans (MSWMP). Secondly, the environment problems lead to economic burden for municipalities, governments and indirectly for the general public as well. In order to decrease further the environmental problems and to create revenues and fund for MSWM, a tax system is introduced. This also stimulates the IMSWMS by promoting the appropriate treatment methods, which can also help in covering the deficit in the municipal budget. In addition, increasing public awareness about different problems associated with MSW may help in source segregation and reduction, thus reinforcing the IMSWMS.

\subsection{A System Dynamics Model for the Existing MSWMS (2001-2006)}

The baseline scenario is simulated for the existing conditions of MSWMS in Delhi between 2001 and 2006. The baseline scenario can be considered as reference scenarios to which other scenarios can be compared. The initial population of Delhi for the year 2001 was $13,850,507$. The decadal average population growth rate for 1991-2001 was $3.93 \%$, which will rise with the compounded net annual growth rate of $2.9 \%$ for the period 2001-2006 (Census of India, 1991; Census of India, 2001; MCD, 2004; DoES, 2006). Data on Gross State Domestic Product (GSDP) for Delhi was colleted for the period 2001-2006 and the annual growth rate and the per capita GSDP were estimated for the same period. The per capita MSW generation rate was taken as $0.45 \mathrm{~kg} /$ day in 2001 (MCD, 2004; CPCB, 2004). The relationship between the per capita GSDP and the per capita MSW generation rate was estimated and then the per capita MSW generation rate was determined. The population and per capita generation rate can give the amount of MSW generated for the city. The recyclables fraction of waste ranges from 13-20\% (Sharholy et al., 2007; MCD, 2005; MCD, 2006; NDMC, 2005; NDMC; 2006). The initial value of recyclables fraction was taken as $15 \%$ for the year 2001. This fraction will grow at rate of 0.005 yearly. It is assumed that the recycling efficiency is $50 \%$. The recycling system involves the formal sector, the municipal body and a large informal sector that consists of many actors such as rag pickers, itinerant buyers, small scrap dealers and wholesalers, which are responsible for recycling of MSW. The informal sector's involvement in recycling of MSW is making it highly efficient. Using the previous data the amount of recycled waste can be estimated, then the amount of collected MSW using $80 \%$ the collection efficiency and the amount of MSW left without collection can be estimated (TERI, 2003).

At present, the three composting plants are operating at about $50 \%$ of its design capacity i.e. 850 t/day because of high operating and maintenance costs compared with open landfills, higher compost cost as compared to the commercial fertilizers and improper separation of the inert materials such as plastic and glass, which degrade the quality of final compost. The remaining waste is dumped in three active landfills. It is assumed that $25 \%$ of waste treated through composting is converted to compost, $10 \%$ is left as residue, which contribute to the MSW going for landfills and the rest lost due to respiration and evaporation (MCD, 2004). The three existing landfills are receiving collected MSW and the remaining residues of the other processes like recycling and composting plants. The funds required for MSWM depend on the funds required for MSW storage, collection and transportation and the annual operating and maintenance costs for landfills and composting plants. It is assumed that MSW storage; collection and transportation consume $90 \%$ of the total funds available for MSWM (MCD, 2004; MCD, 2005; MCD, 2006; NDMC, 2005; NDMC, 2006). The funds available for MSWM depend on the economic growth (GSDP), which in turn influence municipal budget. The per capita expenditure for MSWM depends on population and the funds available for MSWM.

To develop a quantitative model the causal loop diagram is converted to stock flow diagram, which explains the physical as well as the information flows among various elements of the MSWM model. The detailed stock flow diagram of MSWM model is explained in Fig. 2. The MSWMS is depicting the interaction of MSW generation and population, per capita GSDP and per capita MSW generation rate. The system also defines the quantity of MSW collected, uncollected, recycled, composted and disposed of in landfills. In addition, the system determines the funds required for MSWM and the surplus or deficit in MSWM budget. The MSW generated is considered to be product of the two variables: the population $(\mathrm{P})$ and the per capita MSW generation rate $\left(\mathrm{MSW}_{\mathrm{pc}}\right)$. The per capita generation rate increase with the increases in per capita GSDP $\left(\mathrm{GSDP}_{\mathrm{pc}}\right)$, 
which in turn influenced by the economic growth (GSDP), urbanization rate and the living standards of the residents in the city. The annual MSW generation is computed using the following dynamo equations:

$$
M S W_{g}=P * M S W_{p c}
$$

Where, $P=P_{\text {initial }} *(1+\text { annual net growth rate })^{n} ; n$ : year

$$
M S W_{p c}=f\left(G S D P_{p c}, \text { time }\right)
$$

The MSW collected $\left(\mathrm{MSW}_{\mathrm{c}}\right)$ depends on the collection efficiency $\left(\mathrm{C}_{\text {eff }}\right)$ and the quantity of MSW recycled $\left(\mathrm{MSW}_{\mathrm{r}}\right)$, which calculated from the recyclables fraction $\left(\mathrm{R}_{\mathrm{fr}}\right)$ and recycling efficiency $\left(\mathrm{R}_{\mathrm{eff}}\right)$ and affected by the annual growth rate of $R_{\mathrm{fr}}$. The following equations can be used to determine $\mathrm{MSW}_{\mathrm{c}}, \mathrm{MSW}_{\mathrm{r}}$ and MSW uncollected ( $\left.\mathrm{MSW}_{\mathrm{unc}}\right)$

$$
\begin{aligned}
& M S W_{c}=C_{e f f} *\left(M S W_{g}-M S W_{r}\right) \\
& M S W_{r}=R_{f r} * R_{e f f} * M S W_{g} \\
& M S W_{u n c}=M S W_{g}-\left(M S W_{c}+M S W_{r}\right)
\end{aligned}
$$

The amount of MSW composted (MSW $\mathrm{Momp}_{\text {c }}$ ) depends on the operation efficiency for the composting plants. The initial design capacity of composting plants is $850 \mathrm{t} /$ day in 2001, and it is assumed that this amount reduces yearly and reach 500 t/day in 2006. It is assumed that $25 \%$ of waste treated through composting is converted to compost. The amount of MSW, which disposed of at landfills $\left(\mathrm{MSW}_{\text {dis }}\right)$ depends on $\mathrm{MSW}_{\mathrm{c}}$ and $\mathrm{MSW}_{\text {comp }}$

$$
M S W_{d i s}=M S W_{c}-M S W_{\text {comp }}
$$

\subsection{A System Dynamics Model for the Proposed MSWMS (2006-2024)}

Proposed scenario is categorized as policy scenario under which proposed mixture of MSW treatment technologies has been analyzed. For the treatment technologies it is assumed that the capacity enhancement and waste diversion to available treatment methods will be according to the proposed policy of MCD. Following the MSW Rules 2000 (MoEF, 2000), MCD has proposed a scheme for treatment and disposal of MSW in the entire State of Delhi for 2004-2024. The proposed policy aims at both the reduction of final waste to be disposed of as well as reducing the environmental effects of waste treatment. The specific targets, developed with respect to MSW treatment and disposal, are as follows:

- The proposed technologies for MSW treatment are composting, biomethanation and refuse derived fuel (RDF). The different MSW treatment technologies capacity will be increased stepwise in future.

- The current open landfilling practices will be replaced with sanitary landfilling by the year 2011 .
The sanitary landfills and the existing landfills will be provided with the facility of landfill gas recovery system after closure.

The detailed stock flow diagram of the proposed MSWMS model is explained in Fig 3. The MSWMS is depicting the interaction of MSW generation and population, and per capita MSW generation rate. The system also defines the quantity of MSW collected, uncollected, recycled, composted, treated by biomethanation and RDF plants and disposed of in landfills. In addition, the system determines the estimated budget for MSWM for the period 2001-2024. The MSW generated is considered to be product of the two variables: the population (P) and the per capita MSW generation rate $\left(\mathrm{MSW}_{\mathrm{pc}}\right)$. The annual MSW generation is computed using the following dynamo equations:

$$
M S W_{g}=P * M S W_{p c}
$$

Where, $P=P_{\text {initial }} *(1+\text { annual net growth rate })^{n} ; n$ : year

The MSW collected $\left(\mathrm{MSW}_{\mathrm{c}}\right)$ depends on the collection efficiency $\left(\mathrm{C}_{\text {eff }}\right)$ and the quantity of MSW recycled $\left(\mathrm{MSW}_{\mathrm{r}}\right)$. The collection efficiency $\left(\mathrm{C}_{\text {eff }}\right)$ was taken as $80 \%$ during 2001 2005 and it is assumed to reach $90 \%$ then $100 \%$ in 2006 and 2011 respectively, and this means that all MSW generated in 2011 should be collected. The quantity of MSW recycled $\left(\mathrm{MSW}_{\mathrm{r}}\right)$ was calculated from the recyclables fraction $\left(\mathrm{R}_{\mathrm{fr}}\right)$ and recycling efficiency $\left(\mathrm{R}_{\mathrm{eff}}\right)$ and it is affected by the annual growth rate of $R_{\text {frr }}$. The following equations can be used to determine $\mathrm{MSW}_{\mathrm{c}}, \mathrm{MSW}_{\mathrm{r}}$ and MSW uncollected $\left(\mathrm{MSW}_{\mathrm{unc}}\right)$

$$
\begin{aligned}
& M S W_{c}=C_{\text {eff }} *\left(M S W_{g}-M S W_{r}\right) \\
& M S W_{r}=R_{f r} * R_{e f f} * M S W_{g} \\
& M S W u n c=M S W_{g}-\left(M S W_{c}+M S W_{r}\right)
\end{aligned}
$$

The amounts of MSW composted ( $\mathrm{MSW}_{\text {comp }}$ ), treated by biomethanation $\left(\mathrm{MSW}_{\text {biom }}\right)$ and treated by $\mathrm{RDF}$ plants $\left(\mathrm{MSW}_{\text {rdf }}\right)$ are presented in Table and Table. The amount of MSW, which disposed of at landfills $\left(\mathrm{MSW}_{\mathrm{dis}}\right)$ depends on $\mathrm{MSW}_{\mathrm{c}}$, MSW treated

$$
M S W_{d i s}=M S W_{c}-\left(M S W_{\text {comp }}+\mathrm{MSW}_{\text {biom }}+\mathrm{MSW}_{\mathrm{rdf}}\right)
$$

In order to estimate the budget required for proposed MSW disposal and treatment facilities during 2001-2024, it is necessary to estimate the costs required and the revenues resulted from these facilities. The revenues from different disposal and treatment facilities were estimated by considering that the composting market is 1000 Rs./t and the market of electricity generated from different facilities is $3250 \mathrm{Rs}$./Mwh. 


\section{RESULT AND DISCUSSION}

\subsection{Existing Scenario (2001-2006)}

The trend for population and various major variables as MSW generated, collected, uncollected, recycled, disposed of and composted (treated) for the existing scenario is shown in Fig. 4 and Fig. 5. The population of Delhi increased from 13.85 million in 2001 to 15.98 million in 2006 with annual net growth rate $2.9 \%$ and the MSW generated increased from 2.27 million ton in 2001 to 2.73 million ton in 2006 with annual rate $3.75 \%$. The rate MSW disposed of in landfill was increased from $62 \%$ in 2001 to $68 \%$ in 2006 of the MSW generation and the rate of recyclables increased from $7.5 \%$ in 2001 to $7.7 \%$ in 2006, while the rate of MSW composted decreased from $13.7 \%$ in 2001 to $6.7 \%$ in 2006 . The compost production rate decreased from 77 thousands ton in 2001 to 45 thousands ton in 2006 as shown in Fig. 6. In addition the deficit in MSWM budget decreased from Rs. 94 million in 2001 to Rs. 35 million in 2006 and the per capita expenditure on MSWM decreased from 7 Rs./year in 2001 to 2 Rs./year in 2006 as shown in Fig. 7 and Fig. 8.

\subsection{Proposed Scenario (2006-2024)}

The trend for population and various major variables as MSW generated, collected, uncollected, recycled, disposed of and treated for the proposed scenario is shown in Fig. 9, Fig. 10 and Fig 11. The population of Delhi increased from 13.85 million in 2001 to 26.73 million in 2024 and the MSW generated increased from 2.27 million ton (6232 t/day) in 2001 to 5.95 million ton (16300 t/day) in 2024 with annual rate $4.28 \%$. The rate of MSW collected increased from $75 \%$ in 2001 to 84 in 2006 and then to $90 \%$ in 2024 . The rate MSW disposed of in landfill was increased from $62.5 \%$ in 2001 to $77 \%$ in 2006 and then decreased to $56.6 \%$ in 2024 of the MSW generation, while the rate of recyclables increased from $6.5 \%$ in 2001 to $7.2 \%$ in 2006 and $10.3 \%$ in 2024 and the rate of MSW treated decreased from $13.7 \%$ in 2001 to $6.5 \%$ and then increased to $36.8 \%$ in 2024 . The per capita generation rate increased from $0.45 \mathrm{~kg}$ /day in 2001 to $0.48 \mathrm{~kg} /$ day in 2006 and $0.61 \mathrm{~kg} /$ day in 2024 as shown in Fig. 12. The compost production rate decreased from 77 thousands ton in 2001 to 45 thousands ton in 2006 and then increased to 342 thousands in 2026 as shown in Fig. 13.

The electrical energy capacity generated from MSW disposal and treatment facilities is shown in Fig. 14 and Table 8. The electrical energy generation potential increased from 0 in 2001 to 58379.5 Mwh in 2007 and 302275.3 Mwh in 2024. This energy can be used in operating the treatment plants and the extra can be sold to supply a significant portion of the city creating revenue can be added to the municipalities budgets. The estimated costs and revenues of different MSW disposal and treatment facilities are shown in Fig. 15, 16 and 17. As shown in Table 9, the projection revenue produced from different facilities increased from 0 in 2001 to 334.42 (million
Rs.) in 2007 and 2068.6 (million Rs.) in 2024 and this revenue affect positively the budget required for MSW disposal and treatment facilities by covering the costs required for these facilities in 2024, where the budget required is negative because the revenue is more than the costs.

\section{CONCLUSIONS}

A system dynamics model has been developed to analyze the existing (2001-2006) and proposed scenario (2006-2024) of MSWMS in Delhi. The result of this model showed that the generation of MSW in Delhi would increase during 2006-2024 with the increased population at annual rate $4.28 \%$. There is increase in the rate of MSW collected and recycled, while MSW disposed of in landfill will decrease up to $56.6 \%$ in 2024 of the MSW generation with increasing the rate of MSW treated. The per capita generation rate will be $0.61 \mathrm{~kg} /$ day in 2024 and the compost production rate will be 342 thousands in 2024. The electrical energy generation potential from various MSW treatment methods will increase from 0 in 2001 to 58379.5 Mwh in 2007 and 302275.3 Mwh in 2024. The projection revenue produced from different facilities will increase from 0 in 2001 to 334.42 (million Rs.) in 2007 and 2068.6 (million Rs.) in 2024 and this revenue affect positively the budget required for MSW disposal and treatment facilities by covering the costs required for these facilities in 2024, where the budget required is negative because the revenue is more than the costs.

\section{REFERENCES}

Abbott M. D., Stanley R. S., 1999. Modeling Groundwater Recharge and Flow in an Upland Fracture Bedrock Aquifer. System Dynamics Review, vol. 15: 163-184.

Anand S., Dahiyaa R. P., Talyan V., Vratb P., 2005. Investigations of Methane Emissions from Rice Cultivation in Indian Context. Environment International, vol. 31: 469-482. Bach N. L., Saeed K., 1992. Food Self-Sufficiency in Vietnam: A Search for a Viable Solution. System Dynamics Review, vol. 8: 129-148.

Census of India, 1991. Published by Directorate of Census operations, New Delhi.

Census of India, 2001. Published by Directorate of Census operations, New Delhi.

Central Pollution Control Board (CPCB), 2004. Management of Municipal Solid Waste. Ministry of Environment and Forests, New Delhi, India.

Chaerul M., Tanaka M., 2007. A System Dynamics Approach for Hospital Waste Management. Journal of Waste Management. Accepted 11 January 2007.

Dyson B. and Chang N. B., 2005. Forecasting municipal solid waste generation in a Fast-growing urban region with system dynamics modeling, Journal of Waste Management, vol. 25: 669-679.

Department of Science and Technology (DST), 2000. Government of India. Available at: http://dst.gov.in/areport/9900/tifac.htm. 
Ford A., 1996. Testing Snake River Explorer. System Dynamics Review, vol. 12: 305-329.

Forrester JW, 1961. Industrial Dynamics. The MIT Press, Cambridge, Massachusetts, USA.

Forrester JW 1968. Principles of Systems. Productivity Press, Cambridge, Massachusetts, USA.

Georgiadis P., Vlachos D., 2004. The Effect of Environmental Parameters on Product Recovery. European Journal of Operational Research, vol. 157: 449-464.

Guneralp B., Barlas Y., 2003. Dynamic Modeling of A Shallow freshwater Lake for Ecological and Economic Sustainability. Ecological Modeling, vol. 167: 115-138.

Guo H. C., Liu L., Huang G. H., Fuller G. A., Zou R., Yin Y. Y., 2001. A System Dynamics Approach for Regional Environmental Planning and Management: A Study for the Lake Erhai Basin. Journal of Environmental Management, vol. 61: 93-111.

Karavezyris V., Timpe K., Marzi R., 2002. Application of System Dynamics and Fuzzy Logic to Forecasting of Municipal Solid Waste. Mathematics and Computers in Simulation, vol. 60: 149-158.

Mashayekhi A. N., 1993. Transition in New York State Solid Waste System: A Dynamic Analysis. System Dynamics Review, vol. 9: 23-48.

Minegishi S., Thiel D., 2000. System Dynamics Modeling and Simulation of a Particular Food Supply Chain. Simulation Practice and Theory, vol. 8: 321-339.

Ministry of Environment and Forests (MoEF), 2000. The Gazette of India. Municipal Solid Waste (Management and Handling) Rules, 2000, New Delhi, India.

Mohapatra P. K. J., Mandal P., Bora M. C., 1994. Introduction to System Dynamics Modeling. Orient Longman Ltd., Hyderabad, India.

Municipal Corporation of Delhi (MCD), 2004. Feasibility Study and Master Plan for Optimal Waste Treatment and Disposal for The Entire State of Delhi Based on Public Private Partnership Solutions. Delhi, India.

Municipal Corporation Of Delhi (MCD), 2005. Unpublished Data, MCD, Delhi, India.

Municipal Corporation Of Delhi (MCD), 2006. Unpublished Data, MCD, Delhi, India.

Nail R. F., Gelanger S., Klinger A., Peterson E., 1992. An Analysis of Cost Effectiveness of US Energy Policies to Mitigate Global Warming. System Dynamics Review, vol. 8: 111-118.

New Delhi Municipal Council (NDMC), 2005. Unpublished Data, NDMC, New Delhi, India.

New Delhi Municipal Council (NDMC), 2006. Unpublished Data, NDMC, New Delhi, India.

Randers J., 1980. Elements of the System Dynamics Method. Cambridge, Productivity Press, MA, USA.

Richardson G. P., Pugh A.L., 1989. Introduction to System Dynamics Modeling. Waltham, MA: Pegasus Communications Inc.
Saysel A. K., Barlas Y., 2001. A Dynamic Model of Salinization on Irrigated Lands. Ecological Modeling, vol. 139: 177-199.

Saysel A. K., Barlas Y., Yenigun O., 2002. Environmental Sustainability in an Agricultural Development Project: A System Dynamics Approach. Journal of Environmental Management, vol. 64: 247-260.

Sharholy M., Ahmad K., Mahmood G. and Trivedi R. C., 2007. Municipal Solid Waste Management in India Cities - A Review. International Journal of Waste Management, article in press, accepted 12 February 2007.

Sharholy M., Ahmad K., Mahmood G. and Trivedi R. C., 2005. Analysis of Municipal Solid Waste Management Systems in Delhi - A Review. Book of Proceedings for the 2nd International Congress of Chemistry and Environment, Indore, India: 773-777.

Sharholy M., Ahmad K., Vaishya R. C. and Gupta R. D., 2007. Municipal Solid Waste Characteristics and Management in Allahabad, India. International Journal of Waste Management, vol. 27, issue 4: 490-496.

Shi T., Gill R., 2005. Developing Effective Policies for the Sustainable Development of Ecological Agriculture in China: The Case Study of Jinshan County with a Systems Dynamics Model. Ecological Economics, vol. 53: 223-246.

Stave K. A., 2003. A System Dynamics Model to Facilitate Public Understanding of Water Management Options in Las Vegas, Nevada. Journal of Environmental Management, vol. 67: 303-313.

Sterman D., John, Sweeney L. B., 2002. Cloudy Skies: Assessing Public Understanding of Global Warming. System Dynamics Review, vol. 18(2): 207-240.

Sudhir V., Srinivasan G., Muraleedharan V. R., 1997. Planning for Sustainable Solid Waste in Urban India. System Dynamics Review, vol. 13: 223-246.

Talyan V., Dahia R. P., Anand S., Sreekrishnan T. R., 2007. Quantification of Methane Emission from Municipal Solid Waste Disposal in Delhi. Resources, Conservation and Recycling, vol. 50: 240-259.

Tata Energy Research Institute (TERI), 2003. New Delhi, India. Available at: http://www.teri.res.in/teriin/camp/delhi.htm.

Themelis N. J., Kim Y. H., Brady M. H., 2002. Energy Recovery from New York City Solid Wastes. Journal of Waste Management and Research, vol. 20: 223-233.

Vezjak M., Savsek T. Stulher E. A., 1998. System Dynamics of Euthrophication Process in Lakes. European Journal of Operational Research, vol. 109: 442-451.

Vizayakumar K., Mohapatra P. K. J., 1991. Environmental Impact Analysis of a Coalfield. Journal of Environmental Management, vol. 34: 73-93.

Vizayakumar K., Mohapatra P. K. J., 1993. Modeling and Simulation of Environmental Impacts of Coalfield: System Dynamics Approach. Journal of Environmental Management, vol. 42: 59-73. 
Wood T. S., Shelley M. L., 1999. A Dynamic Model of Bioavailability of Metals in Constructed Wetland Sediments. Ecological Engineering, vol. 12: 231-252.
Wu J., Barlas Y., Wankat J. L., 1993. Effect of Patch Connectivity and Arrangement on Animal Metapopulation Dynamics: A Simulation Study. Ecological Modeling, vol. 65: 221-254.

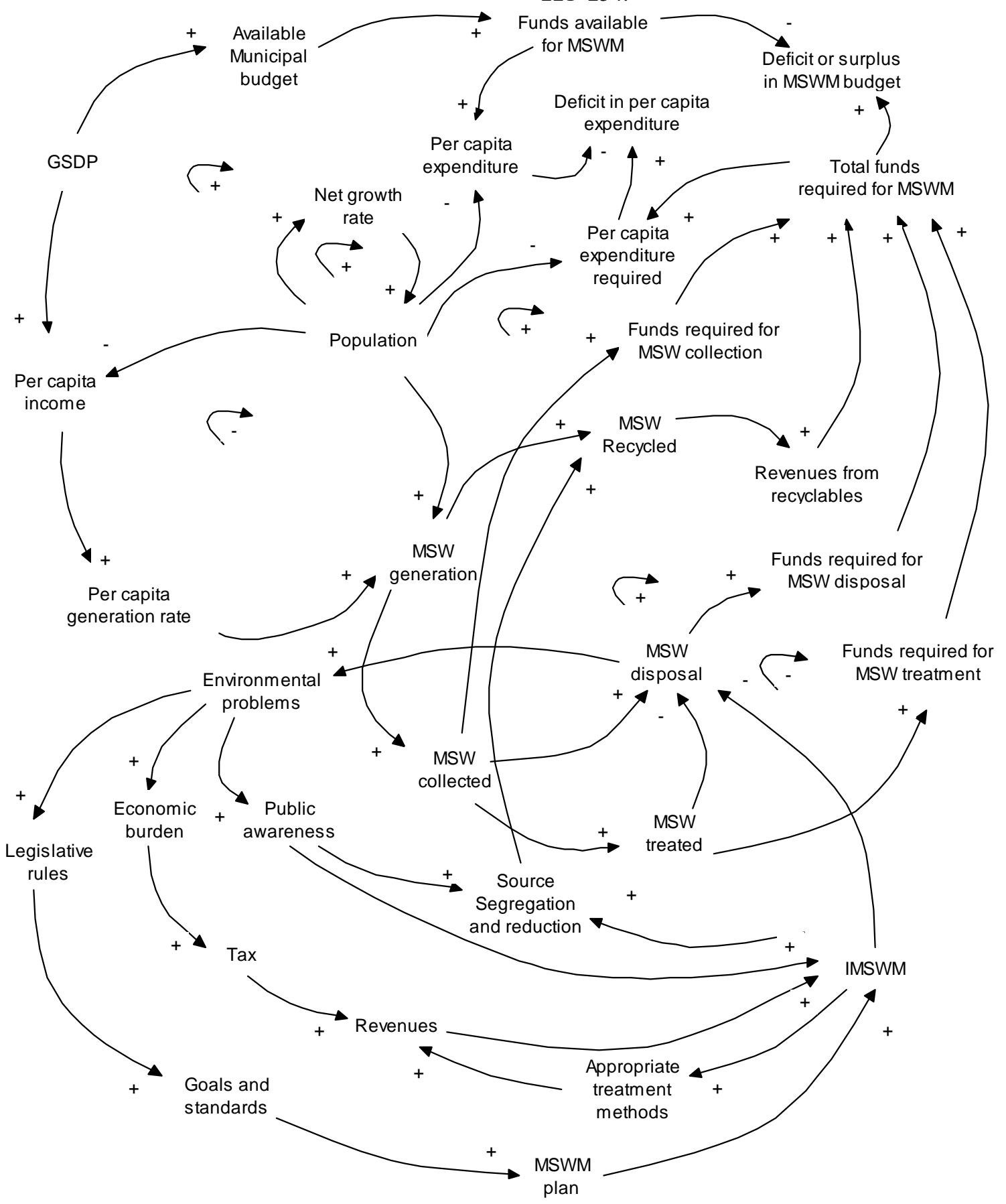

Fig. 1: Causal loop diagram of MSWMS 


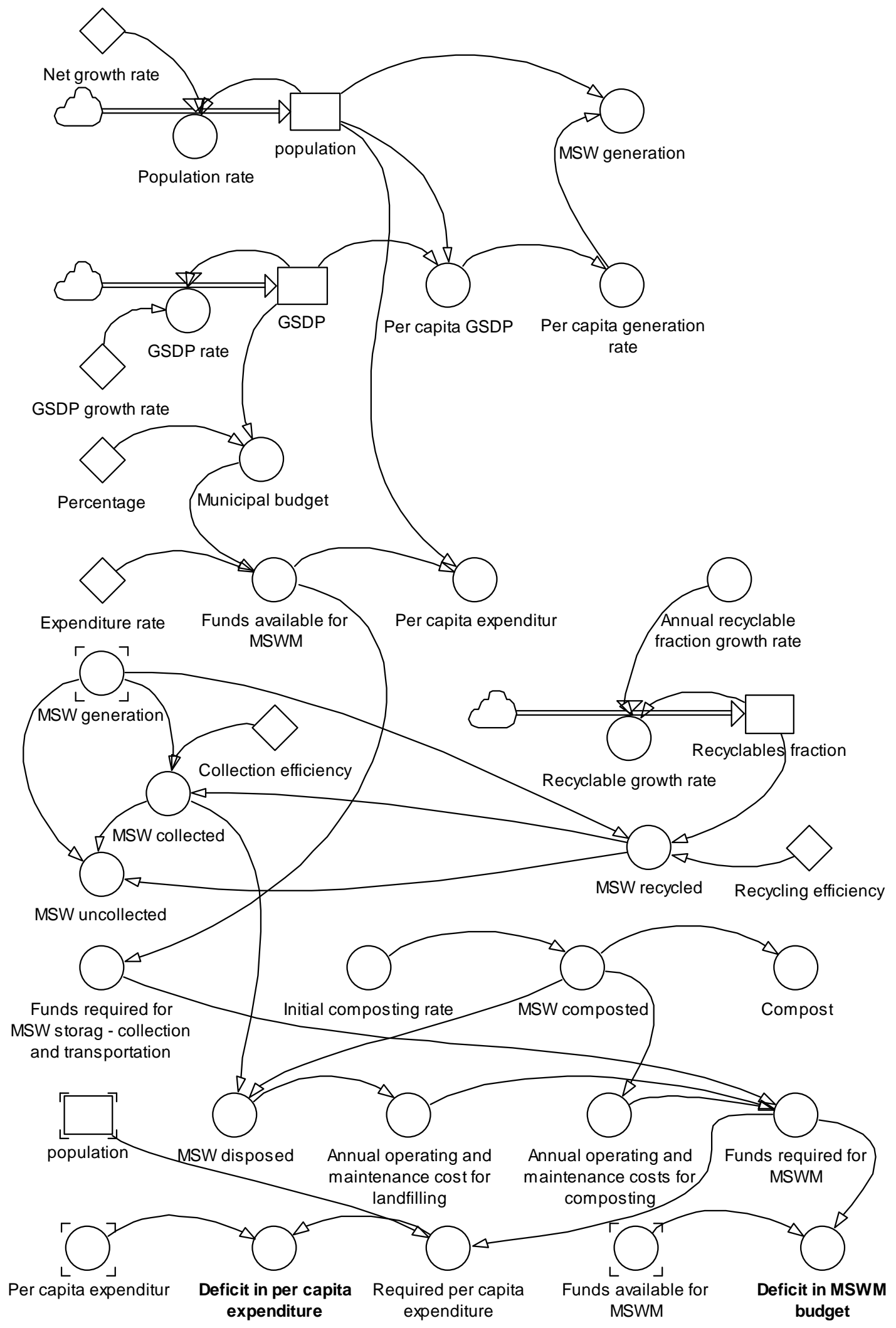

Fig. 2: Stock flow diagram of the existing MSWMS 


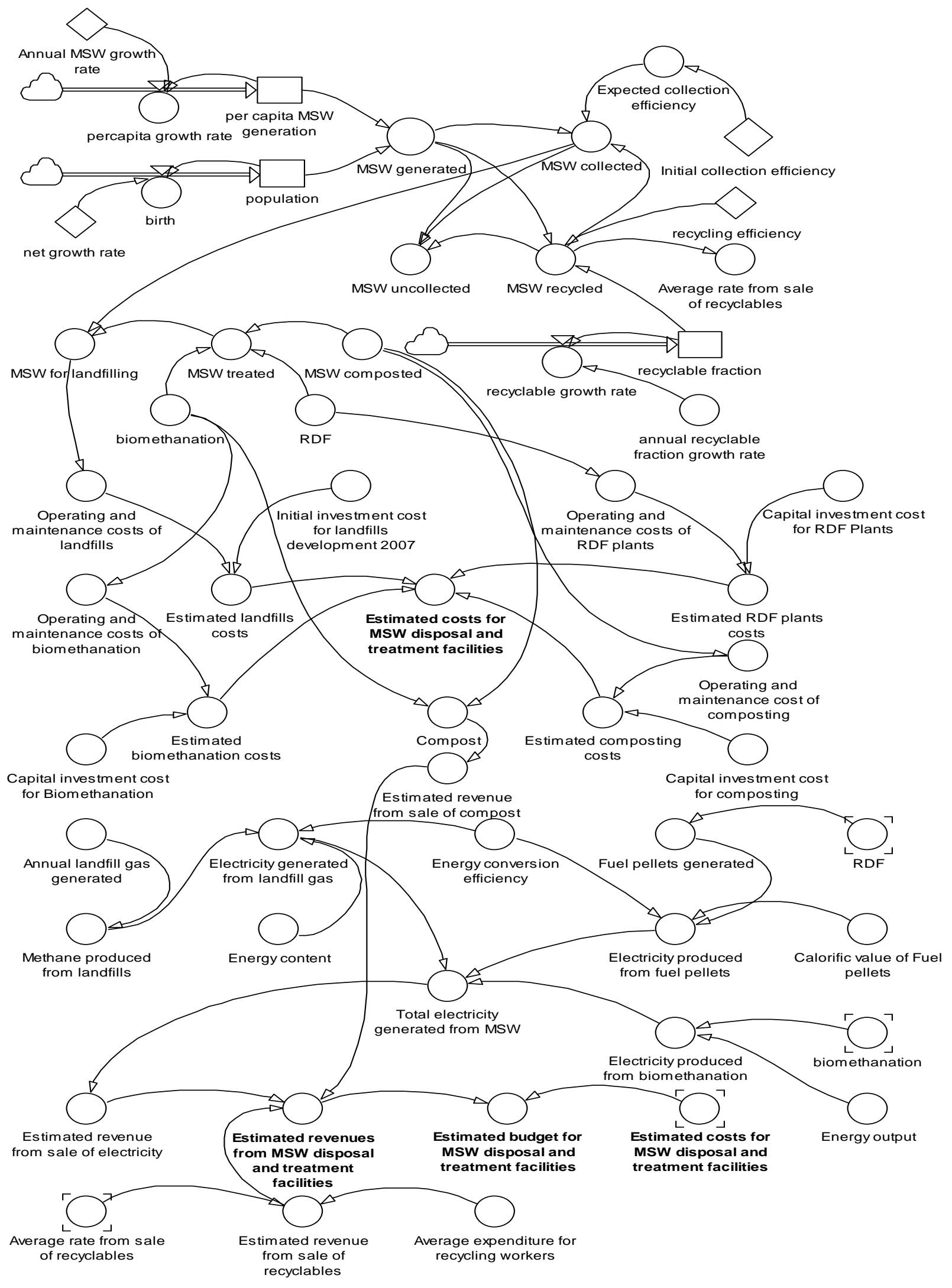

Fig. 3: Stock flow diagram of proposed MSWMS 


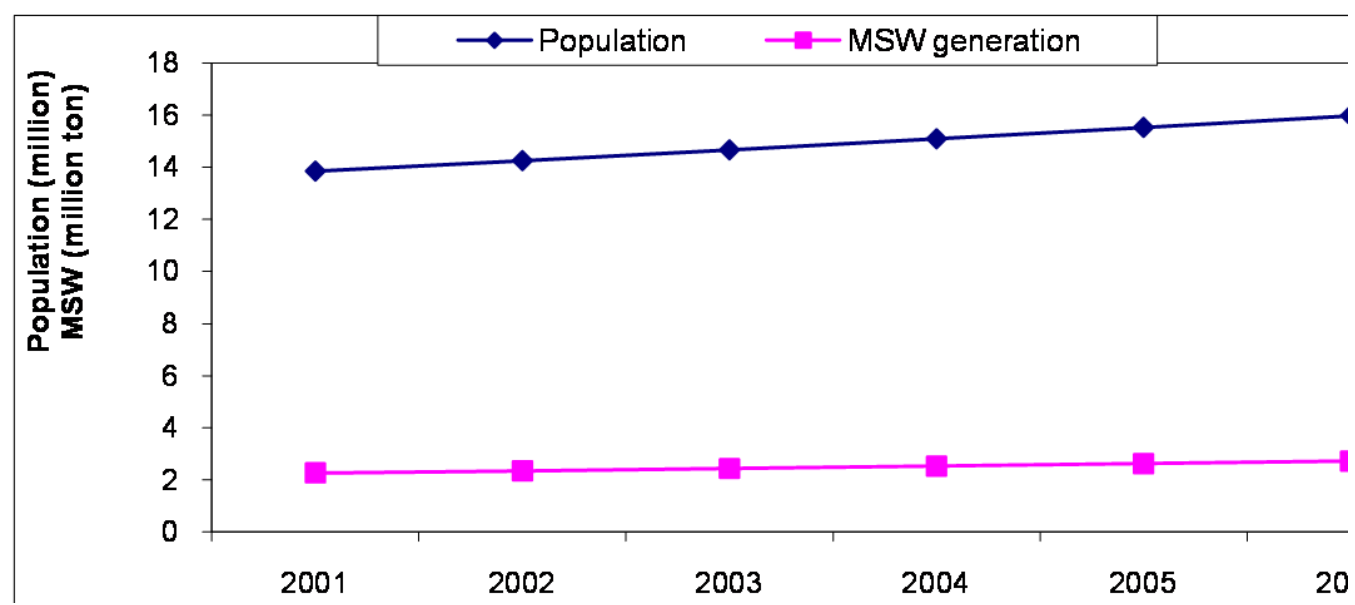

Fig. 4: Trend of population vs. MSW generation in Delhi

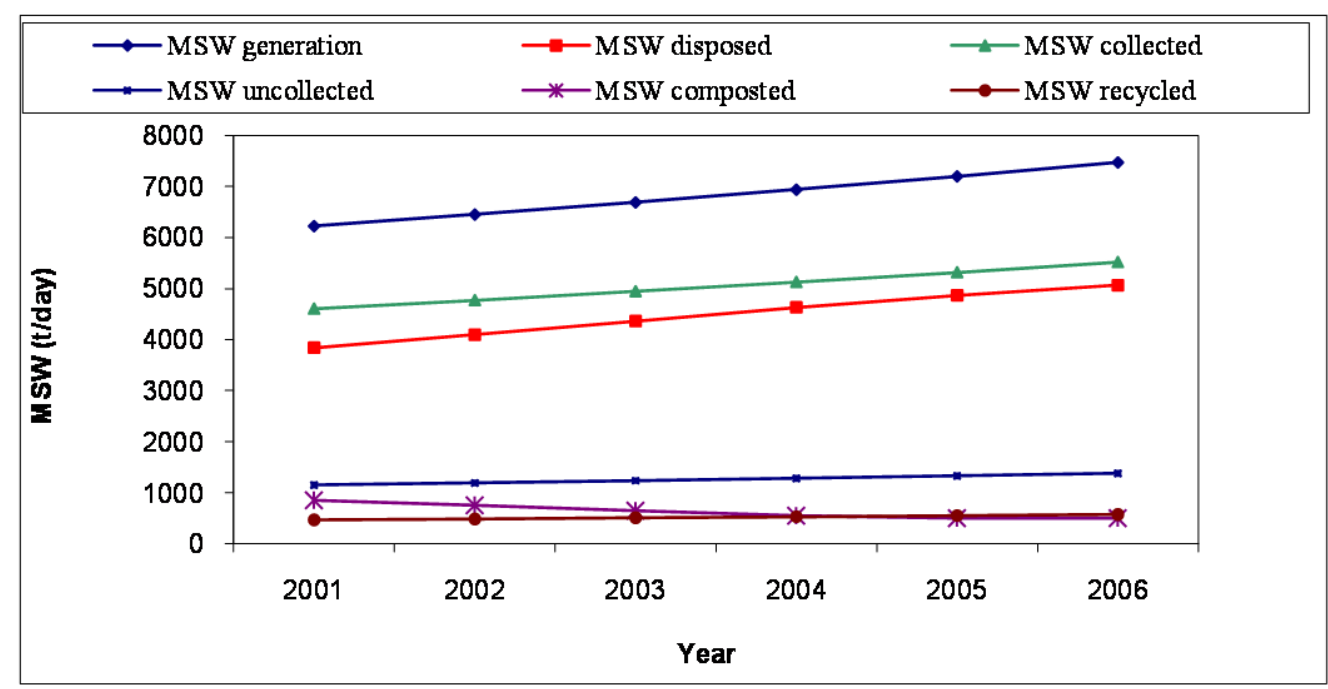

Fig. 5: MSW flow for Delhi city

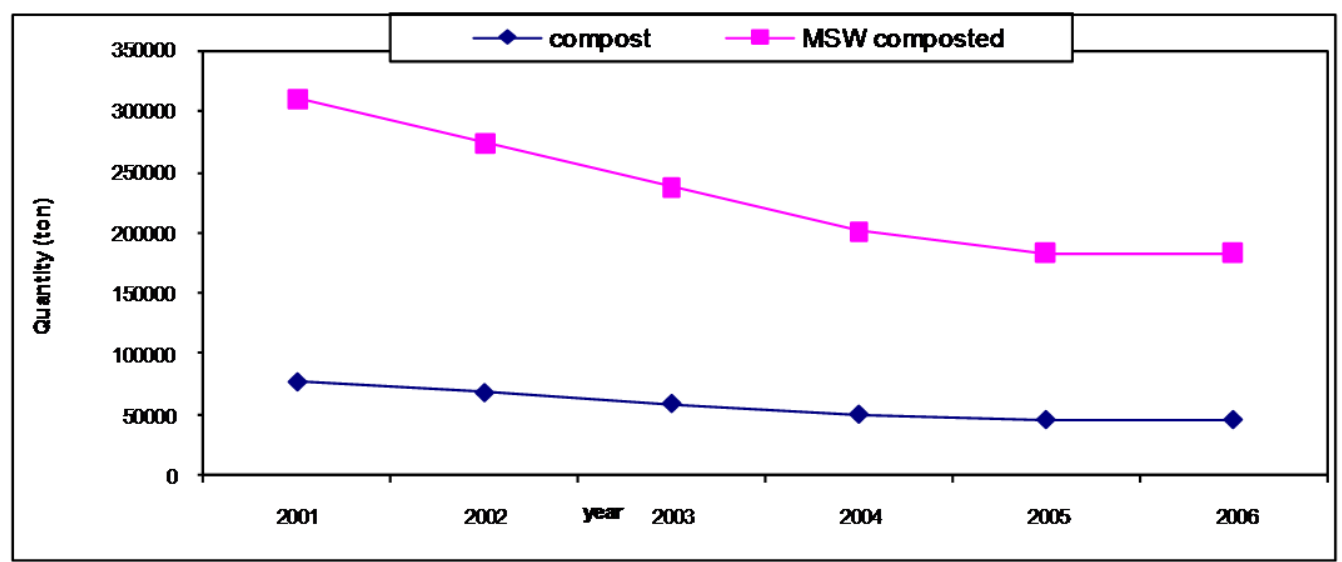

Fig. 6: MSW composted vs. compost produced 


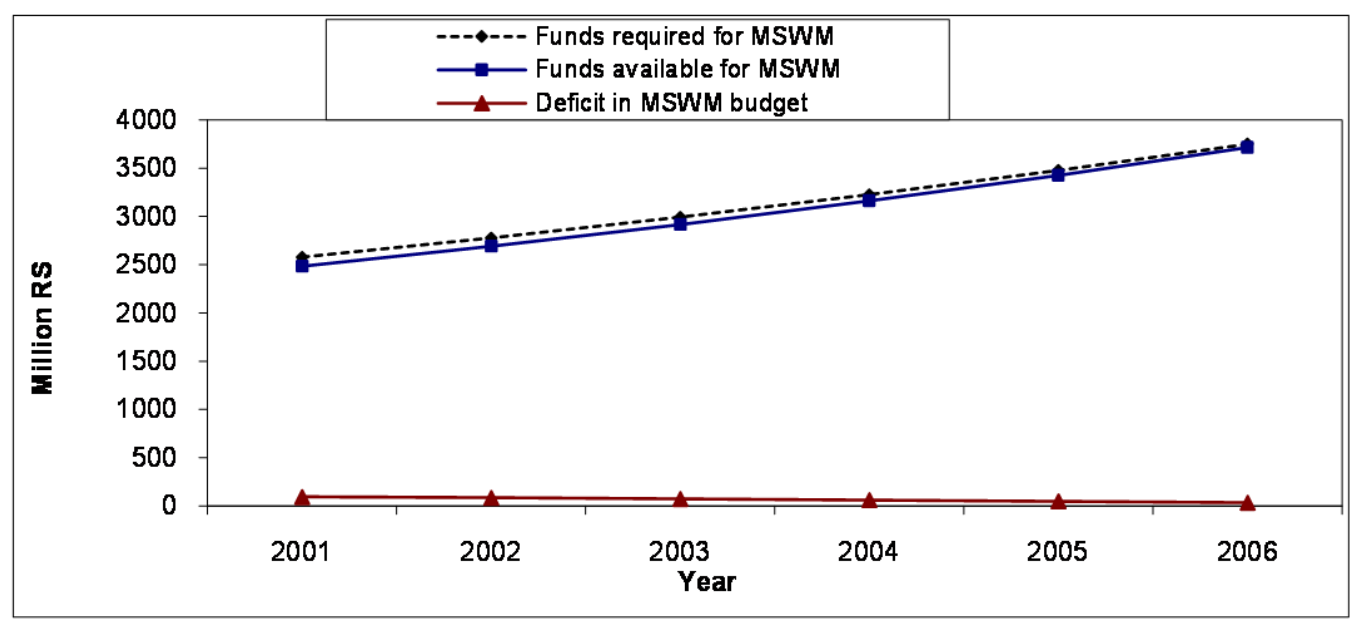

Fig. 7: MSW budget for Delhi

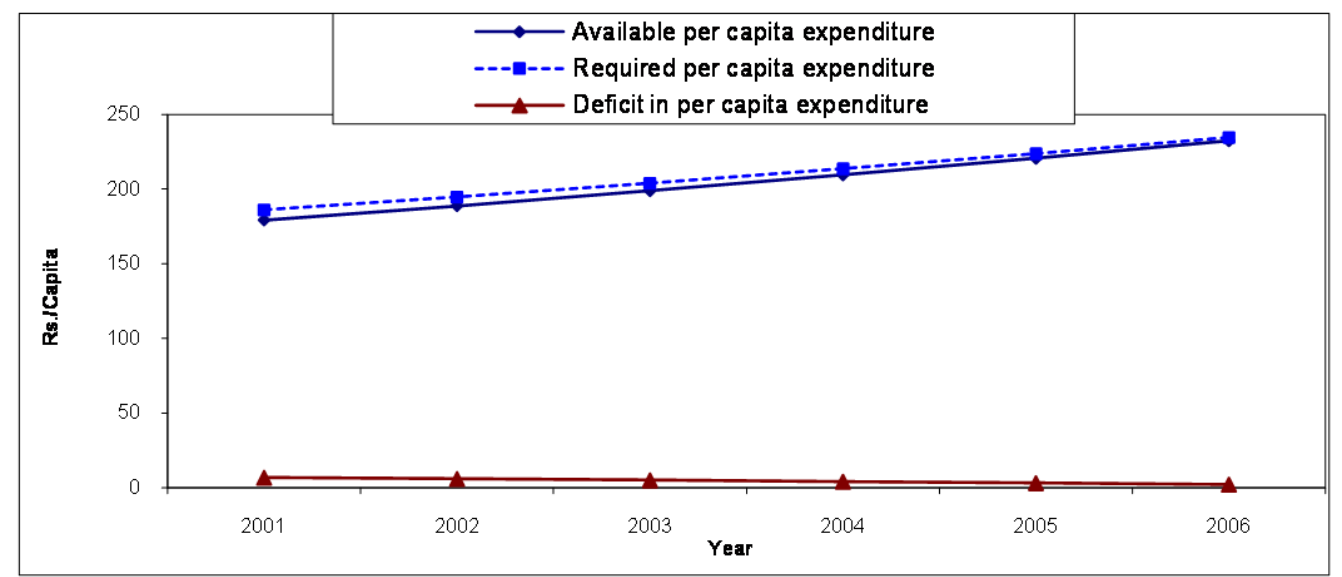

Fig. 8: Per capita expenditure on MSWM

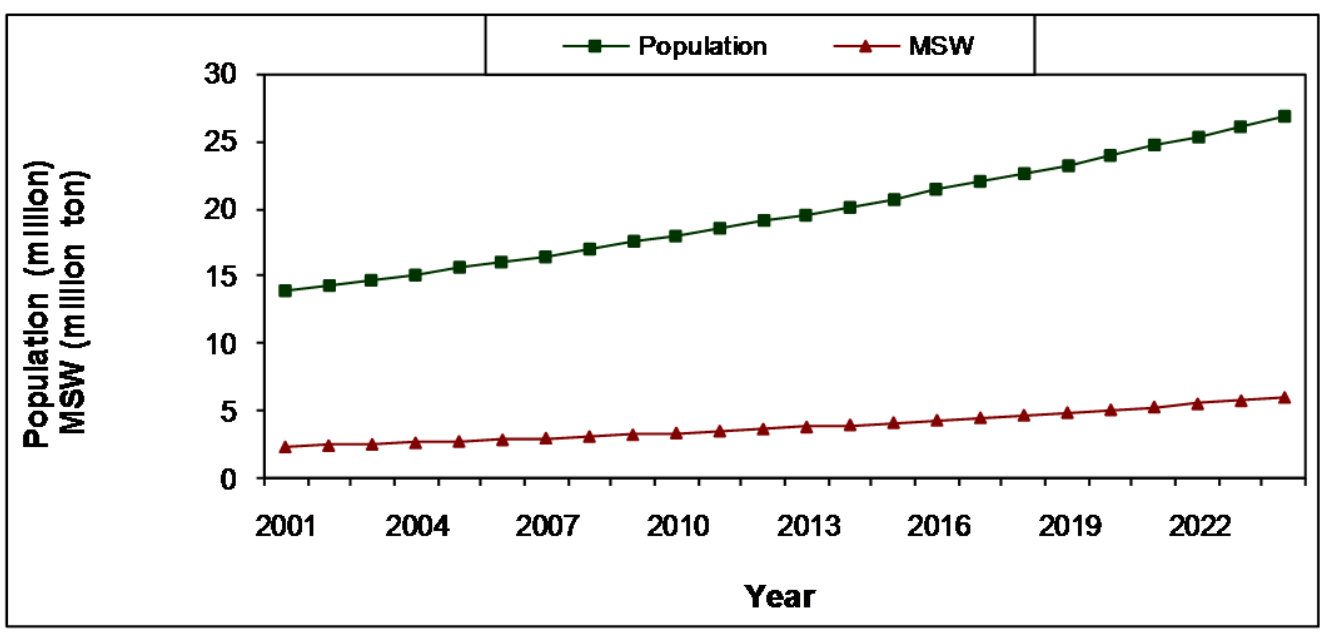

Fig. 9: Projections of population vs. MSW generated 


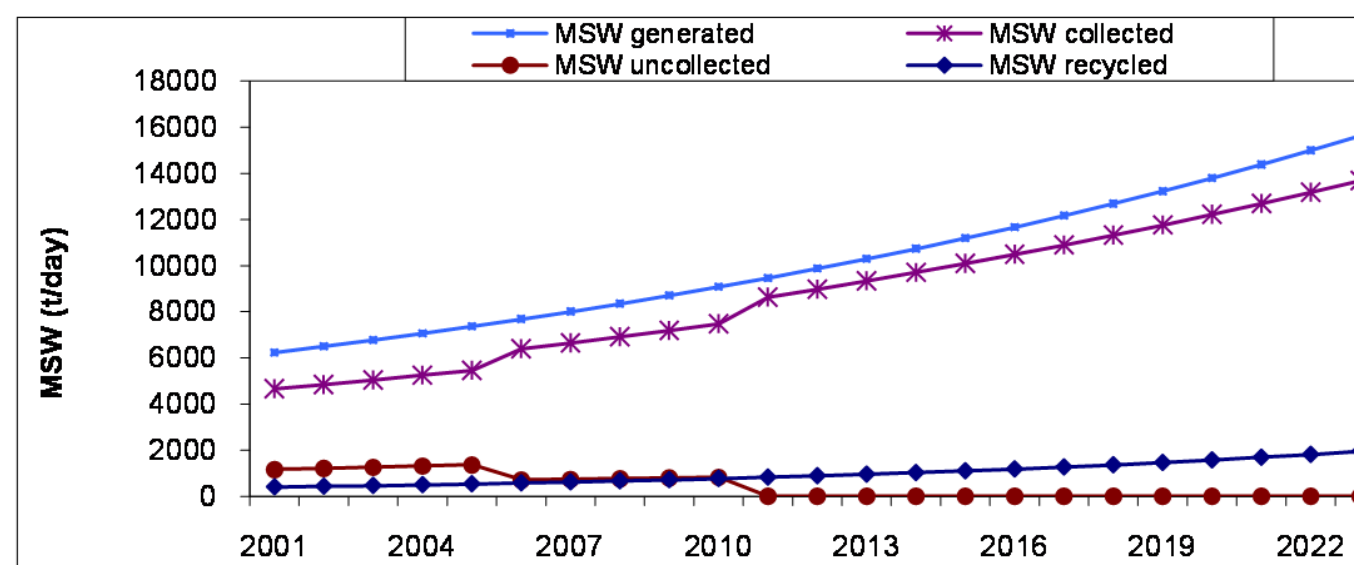

Fig. 10: Projections of MSW flows in Delhi

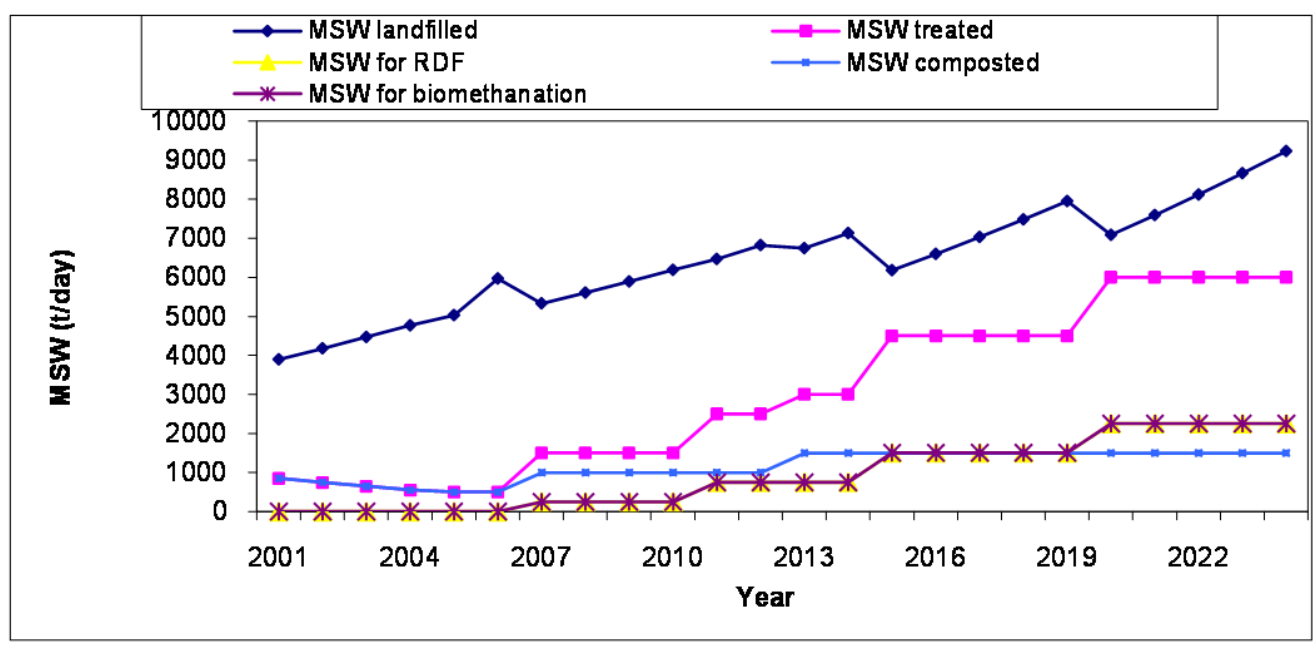

Fig. 11: Proposed MSW disposal and treatment facilities

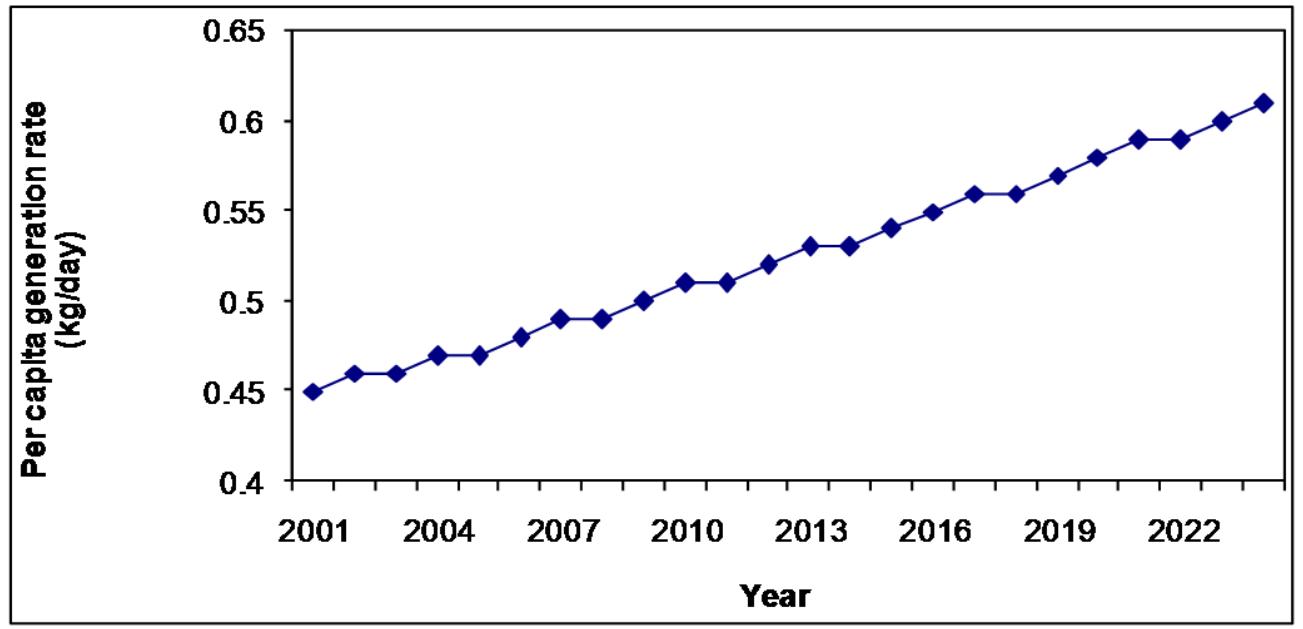

Fig. 12: Projection per capita generation of MSW 


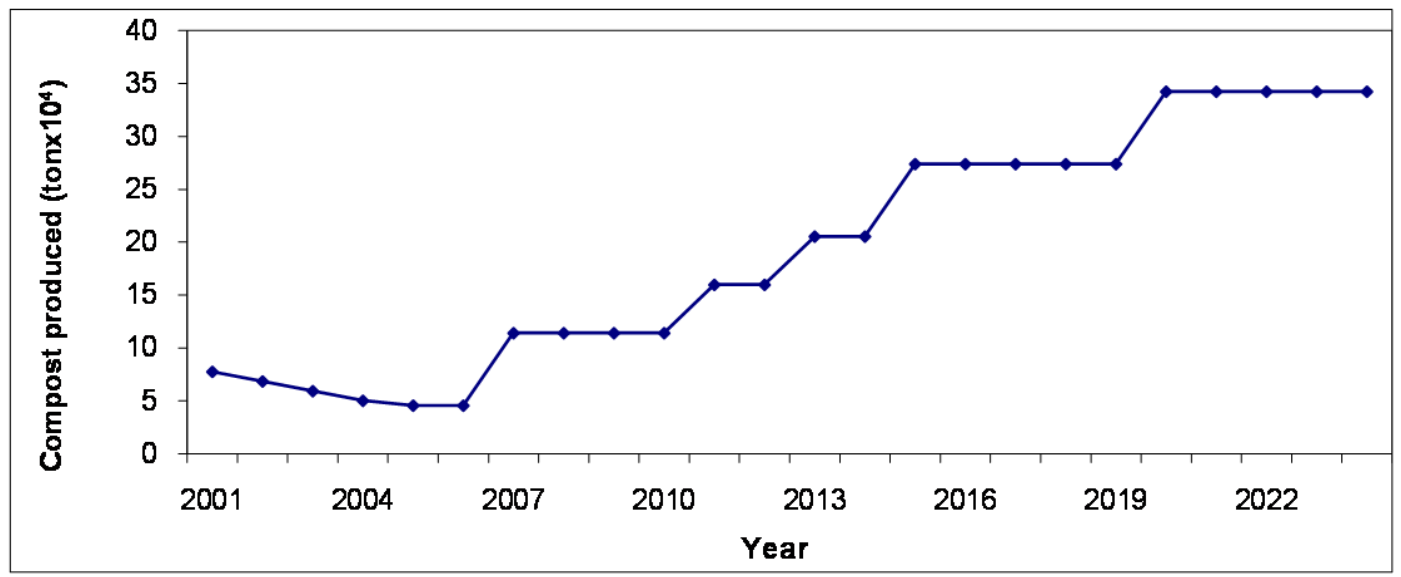

Fig. 13: Projection of compost produced from MSW treatment facilities

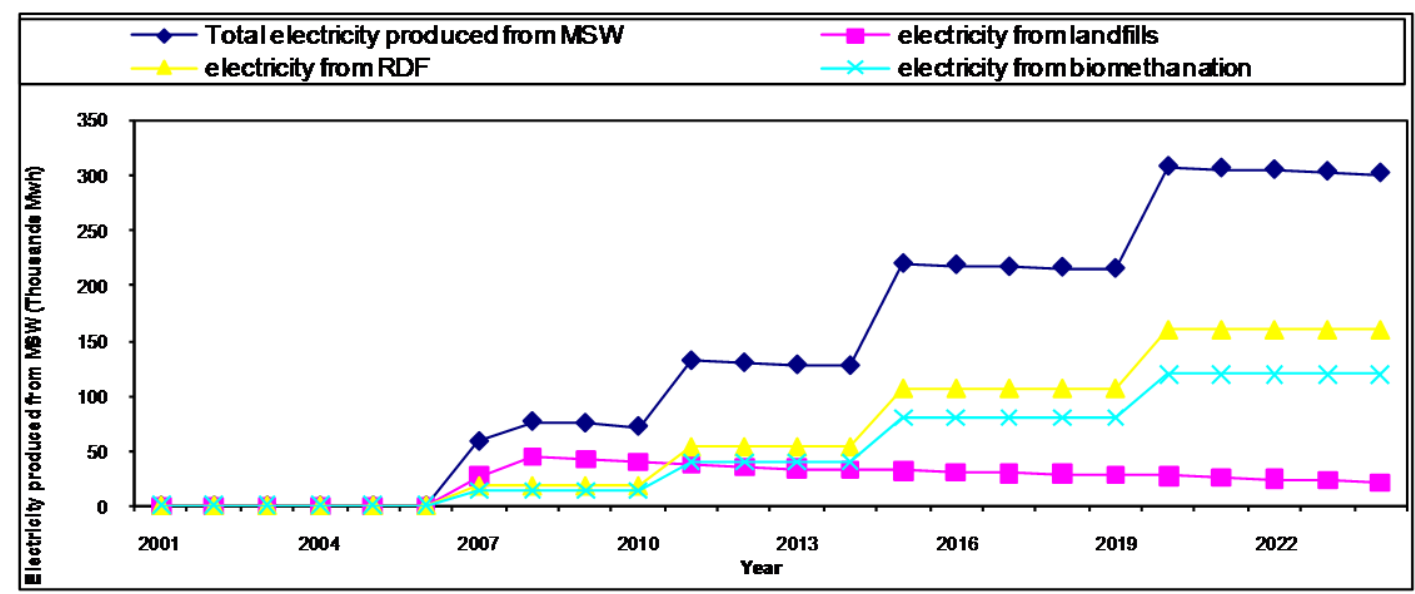

Fig. 14: Projections of electrical energy generated from MSW

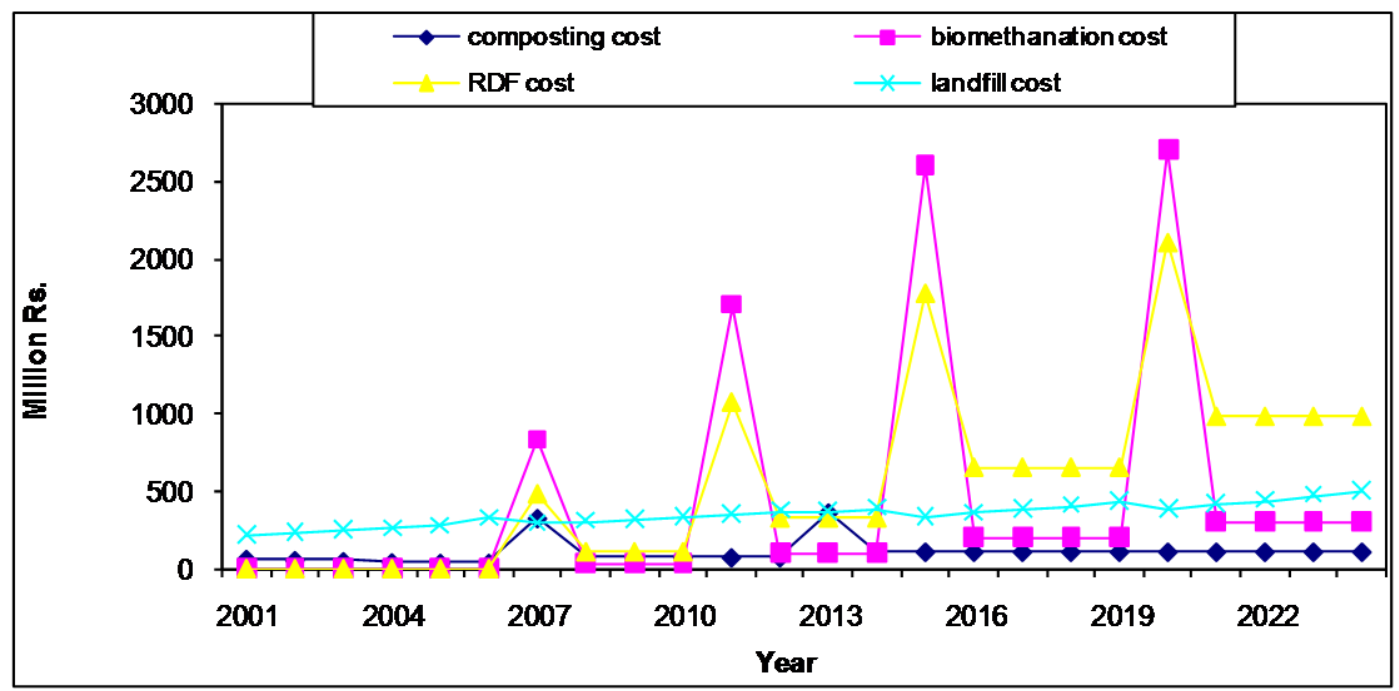

Fig. 15: Projections of the costs for different facilities 


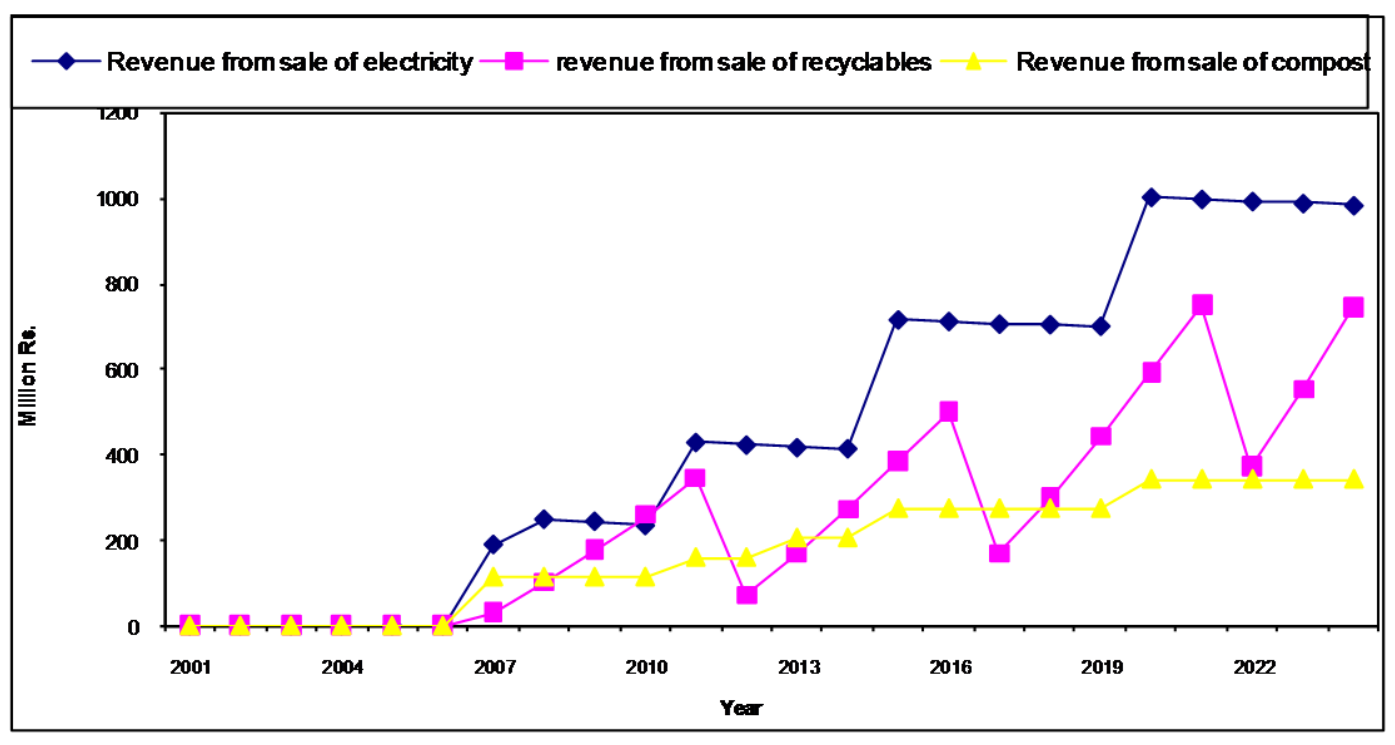

Fig. 16: Projections of the revenues from different facilities

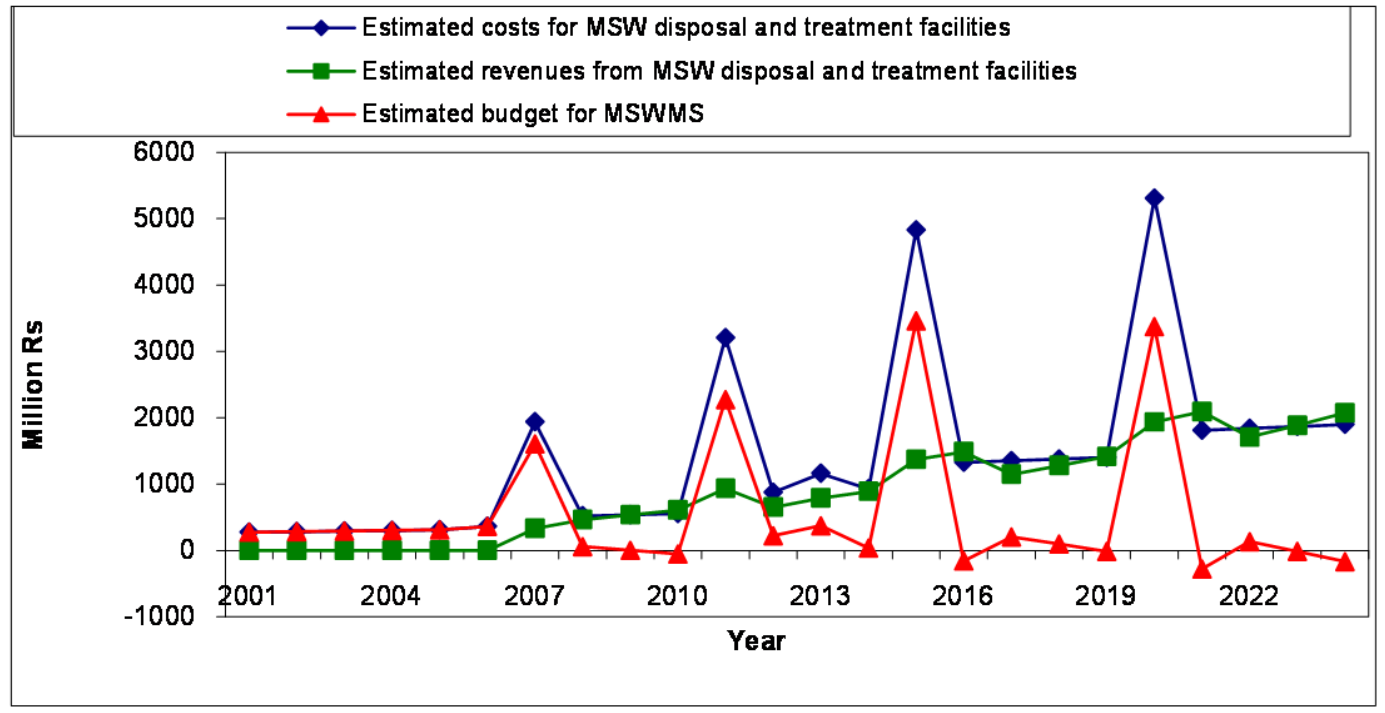

Fig. 17: Projections of the budget required for MSW disposal and treatment facilities 